\title{
Practice on Creative Teaching Mode about Machinery and Equipment of Pulp and Papermaking Course
}

\author{
Ronggang Li \\ College of Papermaking and Plant Resources Engineering \\ Qilu University of Technology \\ Jinan, China \\ Lrg923@163.com \\ Dongmei $\mathrm{Yu}$ \\ College of Papermaking and Plant Resources Engineering \\ Qilu University of Technology \\ Jinan, China
}

\author{
Xiaofeng Xie \\ College of Papermaking and Plant Resources Engineering \\ Qilu University of Technology \\ Jinan, China \\ Chaojun $\mathrm{Wu}$ \\ College of Papermaking and Plant Resources Engineering \\ Qilu University of Technology \\ Jinan, China
}

\begin{abstract}
The course of Machinery and Equipment of Pulp and Papermaking is a compulsory course of pulping and papermaking engineering major, and it is a teaching material with rich content, much knowledge and strong practicality. In addition, the teaching content is dull and tedious. Therefore, there are some difficulties for teachers to teach the course. Based on the network assisted teaching, the reform and practice of teaching mode for the course were carried out in aspects of teaching contents, teaching methods, assessment methods. The practice effect showed that this new kind of teaching mode was beneficial to the development of students' knowledge, mobilized the enthusiasm of students, stimulated students' learning interest.
\end{abstract}

Keywords-Machinery and Equipment of Pulp and Papermaking; Teaching mode; Network-assisted teaching

\section{INTRODUCTION}

The course of Machinery and Equipment of Pulp and Papermaking is a compulsory course of pulping and papermaking engineering major. The main content includes internal structure, working principle, main parts, management and maintenance of commonly used pulp and papermaking equipment [1]. The course is a teaching material with rich content, much knowledge and strong practicality. In addition, the teaching content is dull and tedious. Therefore, there are some difficulties for teachers to teach the course. The goal of this course is to train students' application ability, so as to the students have a solid theoretical foundation and the ability to analyze and solve problems. Therefore, the teaching content of the course should be advanced at the base of maintaining stability of the basic content.

In the previous classroom teaching of the course, most of the teachers had been used a "spoon-fed" "indoctrination style" of classroom teaching. In the traditional teaching method, teachers are the main body in the classroom and students receive knowledge passively only. Monotonous teaching form, less information, single assessment means inhibited the students' initiative and creativity, reduced study interest for the course [2]. In order to change the traditional teaching mode and improve teaching effect, the teaching mode reform should be implemented in classroom teaching. The new teaching mode should combine classroom teaching with the outside school practice. The basic idea is to take the students' development as the center, take application ability development as the teaching standard, take the employment as the guidance, take the education idea innovation as the theoretical support, combine theory teaching and practice teaching in the course teaching [35]. Relying on Key Lab. of Paper Science \& Technology of Ministry of Education (China) in Qilu University of Technology, simplifying and optimizing the teaching content of the course, reforming teaching mode and course assessment methods, using network assisted teaching, classroom teaching methods and means suitable for the course were explored. The practice effect showed that the new kind of teaching mode was beneficial to the development of students' knowledge, mobilized the enthusiasm of students, stimulated students' learning interest, promoted students' autonomous learning, and cultivated the students' ability of innovation and practice [6].

\section{OPTIMIZING THE TEACHING CONTENT OF THE COURSE}

The concept of "one guide and multiple books" was implemented in optimizing the teaching content of the course. The teaching content should reflect students' employment ability development and comprehensive qualities raising, meet the challenge of developing personnel with engineering application type, highlight front-end, academic and skill content, increase the practical training content. According to the students' employment survey, refining the domestic and foreign advanced teaching material, referring to teaching content of the course in similar domestic and foreign universities and colleges, combining the current situation of the papermaking industry, the teaching content of the course was determined and optimized. At the same time, the lecture of the course was carried out relying on the research project hosted by the course instructor and the integration of front academic knowledge. The latest teaching content and teaching reform achievement reflected in the lecture.

According to the students' employment survey, especially through informal discussion with alumni those work in paper- 
making enterprises, alumni generally reflected "Principles of Chemical Engineering", "Machinery and Equipment of Pulp and Papermaking "and "Specialty English for Pulp and Paper Engineering" were helpful for students' future work and students should learn these professional basic courses or professional courses well. The use, management, maintenance and automatic control in papermaking equipment are the weak link for the graduates, but this knowledge is important for the future work. The course of Machinery and Equipment of Pulp and Papermaking is very difficult to understand for the students, mainly because of less practice time, and no actual operation. This is also a challenge for the course instructor, it requests the teacher to have the engineering background first, and have a good lecture secondly. The lecture should be easy understood and accepted for students and reflect the feature of practice, advancement and internationality.

In the preparation of the course lecture, reference material include: the foreign original teaching materials (English teaching materials published in America and Finland), TAPPI teaching video, domestic related curriculum materials, domestic and foreign well-known pulping and papermaking equipment company information, domestic and foreign wellknown pulping and papermaking enterprises information. In addition, the research project hosted by the course instructor and the integration of front academic knowledge turned into the course lecture.

\section{TEACHING MODE REFORM}

The reform of teaching mode is to organize teaching process according to the principle of the combination of classroom teaching, campus practice and outside practice. The basic idea is to take the students' development as the center, take application ability development as the standard, take the employment as the guidance, take the education idea innovation as the theoretical support, combine theory teaching and practice teaching in the classroom. The main body of the course is students, and teachers should be the host of the course The task of the teachers is to organize teaching resources rather than simply imparting knowledge.

Various advanced and practical teaching method were explored in the course. Classroom teaching mainly reflected the key and difficult part of the course. Network teaching platform was used for assisted teaching out the classroom. Review questions and tests of the course could test the learning effect for students. Through the process "classroom teaching-online learning-self testing-summary " , better interaction in the teaching and learning was achieved, and the students' interest in learning was stimulated.

\section{A. Intensively Teaching in Classroom Teaching Creates a Good Effect}

The previous "spoon-fed" "indoctrination style" of classroom teaching mode has been changed, because it will not only occupy too much time, also make the students tired of the course. The optimum principle is to decrease the teaching content, intensively teach those important content, especial important theory and method, to deepen the understanding of theoretical knowledge and achieve the application of the theory. Teachers should first realize characteristic and difficulty of different chapters and then use different classroom teaching methods according to students' ability to understand and accept, such as Intensively Teaching, extensively teaching and omitting some content. Pay attention to the classroom efficiency and learning effect of the students, methods for thinking and solving problems should be focused, so as to cultivate students' ability to solve a problem by using knowledge.

\section{B. Case Driven Teaching Method}

In the teaching process, some research projects hosted by the course teacher did as the teaching case of related content, which richen teaching content. These cases closely combined theory and practice, which greatly stimulated the students' interest in learning, improve teaching efficiency. In the chapter "paper machine forming device", the project "Research and development of an inclined wire paper machine" was as an example to explain composition and structure of the forming device. So students' interest and enthusiasm in learning was unprecedented. In the chapter "Press fabrics of paper machine", the project " Research and development of shoe press paper making felt" was as an example to describe the structure of the press felt, and explain design process of shoe press felt in the high speed paper machine. So the students had a deep impression. In teaching the chapter "Coating machinery of paper machine", the project "Research and development of advanced micro coated paper coating technology" was as an example to explain coating machine and coating technology, and students could grasp the key point of coating technology easily.

\section{Seminar Style Teaching Methods}

The teacher arranged beforehand titles and divided students into several groups. The students looked up research information, gave a summary, completed PPT and elected excellent works each group. In the classroom, research results for each group are presented and discussed, and when a group explained the research result, the other group could take questions. Finally, the teacher gave guidance and summary. This teaching method can cultivate students' ability to find problems, analyze and solve problems and a good spirit of unity and cooperation and the spirit of innovation. For example, in the chapter "Summary of paper machine", teacher designed the question "choose a common paper (such as newsprint, cultural paper, corrugated paper, packaging cardboard, toilet paper, special paper etc.), indicate the configuration of advanced paper machine for produce the paper". In the chapter "Press device of paper machine", the question "the layout and development trend of the press section of high speed paper machine" was given to students. Talking and practice in classroom not only showed cooperation and expression ability of group member, but also strengthen the students' ability of reading literature and analyzing problem.

\section{Scene Simulation Teaching Method}

By using multimedia PPT, photos of equipments, plant video (such as the How paper is made) and animation (such as Voith paper machine animation), scene simulation make the students like be on the scene, more intuitive impression and deep impression. 


\section{E. Practice Teaching}

This course is a very practical course, students have difficulty understanding some teaching contents because no actual operation related equipments. In the teaching process, the teaching difficulty for students is the understanding of pulping and papermaking equipment. At the same time, some of the content is tedious and boring for students. Practice teaching could improve students' learning interest, and be helped to understand and master the professional knowledge. Shandong Key Lab. of Pulp and Paper Engineering had better experimental devices, especially the experimental paper machine, experimental coating machine etc. These devices could provide intuitive understanding for students to learn some contents. Teachers also organized the students in their spare time to visit the relevant paper machinery factory for understand manufacturing, assemblement and installation of the device. Visiting papermaking factory could help students to understand how to manage, use and maintenance of the papermaking equipments. Visiting papermaking fabrics factory could help students to understand how to design and manufacture of the papermaking fabrics.

\section{F. Homework and Review Consolidate the Students' Knowledge}

Through homework design, the professional knowledge and ability of students could be further consolidated. It is helpful for students to learn professional knowledge from the point of solving problem, to master engineering thinking method, to stimulate learning interest, to train ability of analyzing and solving problems independently. The homework, such as "Mounting method of high speed paper machine base plate", "Structure and the use of high speed paper machine headbox", integrated with the practice, and lead students to review and summary many literatures.

\section{G. Combining of Traditional Teaching and Academic \\ Lectures}

Some well-known international and domestic experts and scholars were invited to held academic lectures for students. These lectures introduced new technology and new achievement in the field of papermaking equipment.

\section{H. Application of Network Teaching Means}

Network teaching platform offered by the school could guide students to self-study and enlarge knowledge of students. Pay special attention to the construction of teaching database, many teaching materials accumulated by teachers were uploaded to the network teaching platform, so students could download and study the materials. Domestic and international web sites related the course were recommended to students, which introduced a large number of useful learning materials so contents of the course had the feature of scientific, advanced and international. Especially some enterprise information obtained through the cooperation teachers with enterprises was helpful for students to learn the course, and also help their future jobs.

Course notice, course work, review questions and tests were uploaded to the network teaching platform. But in order to prevent the students copy and plagiarism each other, homework had to write by hand and hand in teachers.
For the convenience of question answering online, teachers established QQ (an online communication software) group including all students and teachers. There are following characteristics making discussion through QQ group: timeliness, exchanging timely between teachers and students strengthened students' understanding for the content of the course; community participation, more student involving into the discussion could improve the students learning enthusiasm and interest; interaction between teachers and students, teachers and students could discuss not only the course, but also professional development and other issues through QQ group.

\section{COURSE ASSESSMENT METHODS REFORM}

Assessment methods of the course had been reformed. Assessment methods had been changed from course examination to integrated assessment mode mainly based on the capacity assessing. Increase the proportion of the usual performance and decrease the proportion of the final exam, this improved enthusiasm and initiative of the students and improved the learning effect.

There are following several parts in the integrated assessment mode: homework scores accounted for $10 \%$, seminar course scores accounted for $10 \%$, classroom test scores accounted for $10 \%$ (take $10 \mathrm{~min}$ in classroom teaching to finish, exam students understanding of the teaching content), course thesis scores accounted for $10 \%$ (students need to read documents, analyze and summarize documents, exercise the students' ability acquiring and summary knowledge), final exam scores accounted for $60 \%$. At the same time, in the final exam, the proportion of test question that exam students' innovation ability and solving problem ability had been improve.

The integrated assessment mode of the course not only stimulated the students' enthusiasm and interest in learning the course, but also cultivated the students' desire and habit to learning actively.

\section{CONCLUSIONS}

Based on the network assisted teaching, the reform and practice of teaching mode for the course of Machinery and Equipment of Pulp and Papermaking were carried out in aspects of teaching contents, teaching methods, assessment methods. Teaching philosophy of the course was "the teacher as the leadership, the student as the main body". The new teaching mode should combine classroom teaching with the outside school practice. Classroom teaching mode used several methods, such as case driven teaching method, seminar style teaching methods and scene simulation teaching method. By means of network learning, homework, after-school self-test and practice after classroom teaching, students' enthusiasm and interest for learning the course were stimulated, so it prompted learning efficiency. The integrated assessment mode suitable for teaching mode reform had been explored and implemented. Update and enrich the teaching materials online, establish scientific and reasonable evaluation rule of the course, let the students participate in the course building; these measures will mobilize enthusiasm, initiative and creativity of the students in the future. 


\section{REFERENCES}

[1] Chen Kefu. Machinery and Equipment of Pulp and Papermaking. Beijing: China Machine Press, 2014

[2] Peng Yonghong. Thinking about University Teaching Mode. Higher education exploration, 2006(4): 59-61

[3] SU Yihua, SUN Yuefa, WANG Furong. Exploration of Innovative Teaching Mode of "Mechanical Drawing And CAD". Journal of Cangzhou Teachers' College, 2011, 27(4): 92-94
[4] Wang Hao, Chen Jun, Zhang Guoqiang. Exploration of innovation teaching reform of "Control and Management of Journal of Traffic". Southeast University, 2012, 14(12): 130-132

[5] Hu Zhidong, Jiang Jihai. Study on Creative Teaching Methods and Practice about Machinery Reliability Design Course for Forest Engineering Major. Forest Engineering, 2013, 29(4): 148-152

[6] Leng Yongsheng. Thinking about Creative Teaching of the Course "Humanity Survival and Development and Nuclear Science”. Science \& Technology Information, 2013, (3): 202-203 